\title{
ARTE DA EXPERIMENTAÇÃO: POLÍTICA, CULTURA E NATUREZA NO PRIMEIRO NIETZSCHE
}

\author{
Anna Hartmann CAVALCANTI ${ }^{1}$
}

- RESUMO: O objetivo deste artigo é analisar as conexões entre o pensamento político de Nietzsche e sua crítica da cultura, tal como desenvolvidos nas notas e ensaios do primeiro período de sua obra, especialmente no ensaio Cinco prefácios a cinco livros não escritos. Trata-se de mostrar como o filósofo procura, a partir de uma singular análise do Estado e da sociedade na Grécia antiga, restituir à experiência política uma dimensão reflexiva em declínio na modernidade.

- PALAVRAS-CHAVE: política; cultura; natureza; Nietzsche.

\section{Introdução}

No final de 1870, ocupado com a redação de sua primeira obra, O Nascimento da Tragédia, Nietzsche desenvolve uma primeira grande sistematização do material já existente, a partir da qual se forma o texto intitulado "Origem e fim da Tragédia" (Ursprung und Ziel der Tragödie; NIETZSCHE, 1997, p.142-203). Esse ensaio é formado por uma reflexão sobre arte e cultura grega, seguida de uma longa seqüência de textos sobre o Estado e a mulher, assim como considerações sobre a formação e desenvolvimento do Estado grego e do Estado moderno. No início de 1871, em uma das versões de sua primeira obra preparada com vistas à publicação, Nietzsche elabora um novo texto sobre arte e política na Grécia Antiga, publicado nas obras completas como fragmento 10(1) (Cf. 1988b, p.333-49), a fim de dar continuidade

1 Doutora em Filosofia pela UNICAMP. Desenvolve, com apoio da FAPERJ, atividade docente e de pesquisa no Departamento de Filosofia e no Programa de Pós-Graduação em Memória Social da UNIRIO. Artigo recebido em set/07 e aprovado em dez/07. 
aos capítulos 1 a 4 de O Nascimento da Tragédia. O principal aspecto abordado nesse texto, no qual é retomada a temática desenvolvida em "Origem e fim da Tragédia", é o de estabelecer uma ligação entre a teoria estética elaborada em O Nascimento da Tragédia e a reflexão sobre a política, analisando tanto a gênese e significação do Estado grego quanto seu papel no desenvolvimento da arte. Embora esse texto não tenha sido incluído por Nietzsche na versão definitiva de sua primeira obra, ele é expressão da importância que, desde o início, a reflexão sobre a política e a sociedade grega antiga ocupa em sua investigação. A relevância desses escritos é confirmada ainda pela escolha de Nietzsche, no final de 1872, em incluir uma versão reelaborada de suas considerações sobre Estado e arte grega no ensaio Cinco prefácios a cinco livros não escritos, presenteado a Cosima Wagner no Natal do mesmo ano. Nessa versão, intitulada "O Estado Grego", Nietzsche introduz um conjunto significativo de modificações: retira os parágrafos iniciais sobre arte apolínea e dionisíaca, que formavam o elemento de conexão com o capítulo 4 de $O$ Nascimento da Tragédia, como também uma longa seqüência sobre a mulher e o Estado grego, na qual é analisada a relação entre Estado e sociedade na Grécia antiga. Essas mudanças diminuem significativamente o papel da arte na reflexão sobre a política antiga e tem como efeito polarizar a análise, criando uma contraposição entre o Estado grego e moderno. Nietzsche inclui, ainda, no mencionado ensaio presenteado a Cosima, o texto "A Disputa de Homero", no qual é analisado o papel central da disputa (Wettkampf) na cultura grega antiga e sua relação com o Estado.

Essa breve exposição do processo de redação de O Nascimento da Tragédia tem como objetivo mostrar como surge, paralelamente ao desenvolvimento de uma metafísica da arte, argumento central da obra, uma perspectiva política de abordagem da cultura e arte gregas. Longe de se ater a uma reflexão estética, Nietzsche desenvolve, nas notas e ensaios do período, uma polêmica crítica à modernidade política que tem como base um estudo singular do Estado e da sociedade na Grécia antiga. Esses primeiros escritos políticos, publicados postumamente, formaram a base fundamental para a reflexão posterior desenvolvida sobre esse tema, tanto em Humano Demasiado Humano, obra da fase intermediária, quanto nas obras do chamado último período de sua filosofia (Cf. HAAR, 1998, p.225-6).

Esses escritos desempenham, ainda, um importante papel no interior das reflexões de Nietzsche, o de formar um testemunho surpreendente do aspecto experimental de sua filosofia. Em uma análise retrospectiva, percebe-se que esses escritos formam um duplo movimento: Nietzsche desenvolve e aprofunda continuamente suas notas sobre o Estado, inicialmente esparsas, a fim de incluir um capítulo sobre o tema em sua primeira obra. Ao decidir não publicá-lo, reformula o resultado mais elaborado a que chegara, o texto publicado como fragmento 10(1), no sentido de uma reflexão sobre o 
Estado grego, construída em contraposição ao Estado liberal moderno. A decisão de não publicá-lo não significa, portanto, o abandono do tema, que é logo em seguida retomado dando origem ao ensaio "O Estado Grego". A análise dos escritos e versões preparatórias a O Nascimento da Tragédia demonstra que Nietzsche se ocupa com um campo temático-conceitual muito mais amplo do que aquele tratado na versão publicada de sua primeira obra e muitas vezes esses núcleos temáticos - como a reflexão sobre Estado e política - são a fonte de reformulações significativas em seu pensamento. Enquanto em O Nascimento Tragédia os conceitos de natureza e cultura são pensados a partir das pulsões artísticas apolíneas e dionisíacas, em "O Estado Grego" Nietzsche politiza sua reflexão sobre a arte e compreende a visão trágica como uma perspectiva filosófica de análise da esfera política. Cabe observar que o texto "O Estado Grego" foi elaborado na forma do ensaio, forma esta que permite desenvolver um processo sempre renovado de reflexão, no qual o pensamento pode se expressar sob o modo de experimentos. Nietzsche procura, a partir de um confronto com a tradição filosófica, pensar novas perspectivas de interpretação da esfera política.

É desta perspectiva que pretendo desenvolver a análise dos ensaios "O Estado Grego" e "A Disputa de Homero", que compõem os Cinco Prefácios a cinco livros não escritos. Esses escritos, que expressam os primeiros resultados das reflexões de Nietzsche ao longo dos anos 1870-1872, devem ser lidos como um ensaio, um experimento do pensamento em relação à modernidade política. É digno de nota o fato de Nietzsche ter escolhido a cultura grega antiga, uma cultura formada por uma estrutura aristocrática e escravista e, ao mesmo tempo, por uma visão trágica da existência, como ponto de partida para sua reflexão. Tratando um tema histórico, explicitado no próprio título - O Estado Grego -, era de se esperar que Nietzsche concentrasse sua análise no âmbito da cultura grega, de sua estrutura política e social. Essa análise forma, contudo, o fundo sobre o qual a verdadeira reflexão é apresentada, a indagação filosófica sobre a relação entre natureza e cultura a partir do contraponto entre cultura antiga e moderna. Nietzsche retoma, de um lado, a abordagem clássica da filosofia política, a passagem do estado de natureza à sociedade, para sua reflexão sobre a formação do Estado. De outro, leva a limites extremos a contraposição entre cultura antiga e moderna, de modo que seu verdadeiro alvo surge com maior clareza: colocar em questão as crenças políticas de sua época, explicitando a historicidade desses valores no confronto com uma cultura diferente. O recurso histórico em "O Estado Grego" possui, desse modo, um sentido estratégico, o de produzir um contraponto histórico entre duas diferentes culturas, a partir do qual Nietzsche procura relativizar, colocar em perspectiva valores centrais e sacralizados da modernidade política. 
Pretendo, neste trabalho, analisar as conexões entre o pensamento político de Nietzsche e sua crítica da cultura, tal como desenvolvidos no primeiro período de sua obra, a fim de mostrar como o filósofo procura, nessas notas e ensaios, restituir à experiência política uma dimensão reflexiva em declínio na modernidade.

\section{A experiência política grega}

Na modernidade, observa Nietzsche em "O Estado Grego", a luta necessária pela vida, o instinto de existir a todo preço, cujo instrumento doloroso é o trabalho, torna-se não somente um objeto digno de respeito, como constitui um dos valores centrais da sociedade, de modo que a "dignidade do homem" passa a estar estreitamente ligada à atividade do trabalho e da produção dos meios de existência. Na modernidade assiste-se à formação de um valor absoluto do homem, fundado no princípio da igualdade e universalidade dos direitos humanos, independente das diferenças entre os indivíduos e de seu poder em dar forma e criar a si próprio. Na interpretação de Nietzsche, a esfera da auto-conservação, a avidez do existir, constitui o critério fundamental da atribuição moderna de valores, conferindo, desse modo, valor em si à espécie homem. A avidez da luta pelo existir, que convive no homem moderno com a necessidade de arte, tende a se expandir e a predominar sobre as demais esferas, isolando a arte e tornando-a uma atividade doméstica, um mero instrumento do ideal de conservação de si. Nietzsche procura chamar atenção para a sacralização, na época moderna, do instinto de auto-conservação, ligado à esfera da utilidade, ao qual passa a estar associado o valor da própria existência.

Os antigos gregos, ao contrário, não viam no trabalho e na necessidade a ele ligada valor algum, assim como não atribuíam ao ser humano em si valor e dignidade, antes o descreviam como seres efêmeros, "filhos do acaso e da dor". ${ }^{2}$ O pessimismo grego foi descrito, em O Nascimento da Tragédia, a partir das palavras do sábio Sileno, companheiro de Dioniso: "O bem supremo te é absolutamente inacessível: é não ter nascido, não ser, nada ser. Em compensação, o segundo dos bens tu podes ter: é logo morrer" (NIETZSCHE, 1988a, p.35). Para o grego, o trabalho é visto como uma necessidade, uma pulsão irresistível para a existência e, ao mesmo tempo, como um ultraje, diante do qual se experimenta o "sentimento de vergonha". ${ }^{3}$ Se há alguma dig-

2 Cf. "Die Geburt der Tragödie" (O Nascimento da Tragédia) In: NIETZSCHE, 1988a, p.35. Salvo indicação em contrário, as traduções são de minha autoria.

3 Ver "Der griechische Staat" In: NIETZSCHE, 1988a, p.766. Trad. bras.: "O Estado Grego" In: NIETZSCHE, 2000a, p.42. Nas próximas citações farei a referência de ambas as edições, primeiramente a edição alemã, em seguida a brasileira. 
nidade na existência humana, esta reside não no impulso de conservação, pelo qual permanecemos ligados à esfera da necessidade, mas na capacidade do tipo homem em criar "além de si". Segundo Nietzsche o sentimento de vergonha é fruto de um saber inconsciente, o da ambivalência da cultura, que forma um mundo próprio, no qual o homem é capaz de transcender a si próprio, e, ao mesmo tempo, permanece ligada à violência e ausência de sentido da natureza. Como observa Hufnagel (2000), a cultura é sempre dissolução e aniquilamento de um mundo natural com leis próprias, em sua progressão há sempre irreparável destruição e rompimento com a natureza.

A cultura cria um mundo novo, cuja condição de desenvolvimento consiste no domínio crescente sobre o impulso natural, a partir do qual surgem formas construtivas de expressão desses impulsos. Nietzsche menciona a este respeito a famosa narrativa de Hesíodo sobre as duas Eris. O poeta descreve tanto a Eris negativa, que leva à guerra e à discórdia, quanto a positiva, que incita os homens não ao combate de morte, mas à disputa e ao crescimento: "Ela conduz até mesmo o homem sem capacidades para o trabalho; e um que carece de posses observa o outro, que é rico, e então se apressa em semear e plantar; o vizinho rivaliza com o vizinho que se esforça para seu bem-estar". ${ }^{4}$ Mas a formação desse mundo novo é inseparável da violência e destruição que constitui a natureza. Nietzsche descreve o processo de usurpação e crueldade que constituiu a gênese do Estado, enfatizando que o direito em sua origem estava fundado na violência, a partir da qual se formam as relações de domínio e hierarquia, assim como a escravidão como expressão das relações de força. Assim como o trabalho, a escravidão é considerada pelo grego antigo como um ultraje e uma necessidade, ela revela o fundamento terrível sobre o qual repousa a cultura: "Para que haja um solo mais largo, fértil e profundo onde a arte se desenvolva, a imensa maioria tem que se submeter como escrava ao serviço de uma minoria" (NIETZSCHE, 1988a, p.767; p.43). Nietzsche observa que essa afirmação não deve deixar dúvida quanto ao valor da existência. A existência humana como expressão de um jogo efêmero de construção e destruição, no qual morte e nascimento não representam o início e o fim, mas estão indissociavelmente ligados, não tem em si valor algum, ela é a experiência da ausência absoluta de sentido. É importante enfatizar aqui a radical ambivalência que Nietzsche atribui à cultura. Como a natureza, a cultura é violência e ausência de sentido, ela expressa uma permanente luta pelo domínio, uma pulsão contínua de expansão e crescimento. Essa ambivalência não foi pensada pela tradição filosófica em todas as suas conseqüências, o que ganha

4 Cf. "A disputa de Homero" In: NIETZSCHE, 2000a, p.69. 
uma expressão surpreendente no ensaio através da insistência e crueza com que Nietzsche desenvolve sua argumentação. Essa crueza tem o papel, como indica Hufnagel (2000, p.53), de expor os traços brutais do processo civilizatório, traços estes que o movimento esclarecido procura apagar tanto da face da natureza quanto da cultura, através da crença no poder ilimitado da razão e na perfeição crescente do espírito. Enfatizando a ambivalência que caracteriza o desenvolvimento da cultura, Nietzsche explicita, no ensaio "A disputa em Homero", a ilusão contida na crença que a humanidade é o que separa o homem da natureza. Não há de fato esta separação, o "natural" e o "humano" estão entrelaçados de modo indissociável. Em suas ações mais nobres e dignas, assim como nos atos cruéis e terríveis, considerados desumanos, o homem faz parte da natureza, e é possível, observa Nietzsche, que mesmo esses atos terríveis constituam o solo fecundo de onde pode surgir a humanidade sob a "forma de emoções, feitos e obras" (NIETZSCHE, 2000a, p.65). A ênfase na relação entre os aspectos destrutivos e criadores, indica a necessidade em pensar a cultura não como uma negação, que não pode deixar de ser abstrata, mas como uma aspiração de integração com a natureza.

Assim como a cultura, a gênese do Estado é marcada tanto pela crueldade e violência quanto pelo impulso de criação e crescimento. Nietzsche observa, em relação ao primeiro aspecto, que a crueldade da civilização "pertence à própria natureza do poder" (NIETZSCHE, 1988a, 768; p.44). Percebe-se aqui uma estreita relação entre os conceitos de natureza, poder e Estado, a partir da qual se torna visível o diálogo estabelecido com a tradição do pensamento político. Niezsche desenvolve sua reflexão como uma contraposição às "falsas" teses modernas sobre a gênese e a significação do Estado. Trata-se aqui das teorias modernas do contrato social, encontradas em pensadores tão diferentes como Hobbes e Rousseau, segundo as quais o Estado nasce de um contrato com os indivíduos em estado de natureza. Hobbes caracteriza o estado de natureza como um estado de guerra de todos contra todos, no qual a conservação de si, a busca dos bens necessários à vida, assim como de tudo que proporciona prazer, é a medida do direito. Esse estado, no qual impera a violência generalizada, a busca permanente de novos meios de destruição do próximo, resulta no estabelecimento do contrato, pelo qual a concessão do poder ao soberano garante a paz e a conservação da vida (HOBBES, 1983, Cap. XIII). Diferentemente da teoria hobbesiana, a gênese do Estado é descrita em "O Estado Grego" como uma permanente luta pelo domínio, um desejo selvagem de destruição que devasta comunidades inteiras, ao mesmo tempo que coage os grupos a se organizarem impondo uma determinada hierarquia e estrutura de poder. Não é portanto o contrato, pelo qual os indivíduos transferem seus direitos a um governante em troca da garantia de preservação da vida, mas uma luta de 
expansão e domínio, a afirmação pela força de um grupo determinado, que funda o Estado. Nietzsche se opõe, assim, à concepção hobbesiana de poder, segundo a qual este é entendido, segundo uma lógica utilitária, como um meio voltado para um fim, o de obter os bens desejados (Cf. ANSELLPEARSON, 1997, p.60). O objetivo das forças e energias da vida não é, segundo a interpretação nietzscheana, a conservação de si, mas uma expansão e crescimento contínuos, um movimento de auto-superação.

O tipo guerreiro que constitui o Estado é caracterizado como uma força conquistadora e agressiva e, ao mesmo tempo, modeladora, capaz de dar forma a uma matéria ainda disforme, que imprime os limites e a estabilidade da forma a uma população até então nômade e selvagem. Em uma referência ao pensamento hobbesiano, Nietzsche observa que o bellum omnium contra omnes, que caracteriza o estado de natureza, torna impossível a formação de uma organização social que ultrapasse os limites da família. O Estado tem o papel de reorientar as manifestações da "guerra de todos contra todos" criando as condições para o desenvolvimento da sociedade e das expressões artísticas. Enquanto na sociedade o instinto de domínio e expansão é limitado e circunscrito às regras e exigências sociais, na guerra este bellum encontra espaço para sua livre manifestação. Nietzsche descreve a devastação e brutalidade das batalhas, nas quais os instintos de domínio e crueldade reprimidos na convivência social se liberavam e formavam o princípio da justiça de guerra: a execução dos combatentes, a escravização de mulheres e crianças, são expressão do que constituía o direito do vencedor.

Cabe ressaltar, a esse respeito, o diálogo que Nietzsche estabelece com Platão na passagem onde aproxima a formação do Estado ao direito de guerra que caracteriza a época de "apogeu" da moralidade grega: "O vencido pertence ao vencedor, com mulher e filho, com bens e sangue. É a violência que dá o primeiro direito, e não há nenhum direito que não seja em seu fundamento arrogância, usurpação, ato de violência" (NIETZSCHE, 1988a, p770; p.46). Não se pode deixar de perceber aqui uma alusão ao discurso de Calicles, no Górgias, ou ao diálogo entre Sócrates e Trasímaco na República. O objetivo de Platão consiste em contrapor à teoria do direito do mais forte, defendida por Trasímaco, a verdadeira essência do justo, que se constitui como tarefa do Estado ideal (PLATÃO, 1996, 338c). Nietzsche utiliza a teoria da força para analisar a gênese do Estado, a fim de mostrar que não é a necessidade dos homens, que não se bastam a si próprios e precisam de muitas coisas, mas as relações de força que estão na base da formação da sociedade. Mesmo supondo a existência de um "um instinto de sociabilidade" no indivíduo, é imprescindível "o pulso de ferro" do Estado para produzir uma estrutura social organizada. O desenvolvimento da sociedade tem como condição, desse modo, a determinação e coerção do aparelho estatal. A afirmação da equivalência entre direito e usurpação faz parte da ambivalência da cultura que Nietzsche procura sublinhar nesse ensaio. 
Nietzsche se refere à surpreendente capacidade de organização de um Estado que se forma pela guerra e pela destruição como expressão de uma "necessidade" e "intenção profunda" da natureza (NIETZSCHE, 1988a, p.770; p.46). Na Grécia antiga, a subordinação de todos os interesses individuais ao Estado, a sua tarefa de regulamentar e organizar educação dos cidadãos, assim como dos jogos e festividades religiosas e artísticas, é expressão de uma relação orgânica entre os indivíduos e a Cidade. Em "A disputa em Homero", é descrito o papel central que a disputa e a busca da perfeição desempenhavam na cultura grega antiga, assim como sua importância na manutenção do equilíbrio do poder estatal. A disputa consiste em um jogo permanente entre forças rivais, cujo objetivo não é alcançar um estado final, no qual um combatente conquiste e detenha a supremacia. Segundo as regras gregas é necessário afastar o indivíduo que se mantém na posição vencedora, pois o princípio fundamental era a manutenção permanente da disputa, como meio de proteção contra os perigos da supremacia de um só. A disputa era também o princípio que orientava a educação dos jovens, cujos dons deviam desabrochar e crescer na luta e na competição, através das quais eles não somente desenvolviam sua personalidade, mas participavam dos jogos e festividades organizados pela Cidade. Ao mesmo tempo que a disputa incentivava a ambição e o desejo de glória dos indivíduos, ela estava estreitamente associada e orientada aos interesses da Cidade, de modo que os impulsos individuais se integravam à comunidade e encontravam seus limites. A disputa caracterizava, enfim, tanto a formação dos artistas quanto o modo de apresentação das obras de arte, encenadas sob a forma de um grandiosa competição, da qual participavam grandes poetas, músicos e dramaturgos.

O Estado torna possível, desse modo, não apenas o desenvolvimento de indivíduos, que afirmam através da disputa seu talento e singularidade, mas do artista e da criação da obra de arte. A articulação entre estes dois extremos das manifestações culturais, a crueldade do domínio e das guerras, de um lado, e a introdução de um princípio na formação dos cidadãos apoiado na contínua superação de si, de outro, é expressão de uma concepção de natureza que Nietzsche procura opor à tradição do pensamento político presente nas entrelinhas de seu texto. A essência da natureza e da vida não repousa no "instinto de existir a todo preço" ou, em outras palavras, na busca da conservação de si, mas em um permanente impulso de expansão e crescimento, no desejo de intensificação e superação dos estados já alcançados, o que supõe uma relação de antagonismo e luta. O crescimento está essencialmente ligado à relações antagônicas entre grupos ou tipos de homens, entre indivíduos ou até mesmo entre diferentes possibilidades no interior do mesmo indivíduo (VAN TONGEREN, p.3). Vitalidade de um organismo, de um indivíduo ou cultura só existe, para Nietzsche, no 
âmbito de relações de forças que procuram se expandir e que encontram, em seu caminho, resistência e oposição. Força e saúde estão, portanto, ligadas à afirmação desta luta e a fraqueza a sua negação. É no âmbito desta concepção da natureza que Nietzsche irá desenvolver sua reflexão sobre política e cultura a partir da distinção entre forças que conservam e forças que afirmam e que intensificam a vida.

\section{A modernidade política}

Enquanto os gregos se expressavam com surpreendente franqueza sobre o valor da existência humana e a necessidade de produzir os meios necessários à subsistência, a consolidação de uma nova esfera de valores na modernidade, o princípio de igualdade e dignificação do trabalho, desenvolve-se através de uma atividade de dissimulação. Os valores de dignidade do homem e dignidade do trabalho, a crença no progresso tecnológico e sua promessa de um futuro liberto de toda desigualdade e injustiça, escondem uma contradição: dignidade na sociedade do bem-estar, na qual a felicidade é identificada com segurança e conforto, está estreitamente ligada a fins utilitários, o discurso da dignidade do trabalho torna-se instrumento de estratégias político-sociais de dominação. De forma irônica, sem esclarecer a inversão no uso dos conceitos, Nietzsche assim resume seu diagnóstico da modernidade: em um mundo onde todos se comportam como escravos, a palavra "escravo" causa mal-estar e horror. É com essa frase, cuja intenção de provocação não podia ser mais explícita, que se inicia o ensaio "O Estado Grego" (Cf. HUFNAGEL, 2000, p.42). Com essa inversão de termos, Nietzsche caracteriza não apenas o trabalhador moderno, livre e possuidor de direitos iguais, mas também o empresário, denominado "aristocracia do dinheiro", assim como a burocracia estatal. O uso freqüente da expressão "dignidade do trabalho" acompanhada de "dignidade do homem" tem o papel de enfatizar o processo de generalização e difusão do ideal de auto-conservação, a partir do qual se dá a caracterização da moderna sociedade industrial como um modo dissimulado de escravidão.

A escravidão não desapareceu da sociedade moderna, ela sobrevive de forma dissimulada e é por esta razão que provoca "mal estar e terror". Em $O$ Nascimento da Tragédia, em um capítulo no qual analisa o fenômeno da moderna sociedade do trabalho, Nietzsche chama atenção para aquilo que "se esconde" nos valores de igualdade e dignidade do trabalho: "a civilização alexandrina precisa de uma casta de escravos para poder existir e durar: mas nega, em sua consideração otimista da existência, a necessidade de tal casta, e, por isso, quando o efeito de suas belas palavras de sedução e apaziguamento sobre a 'dignidade do homem' estiver gasto, irá pouco a 
pouco ao encontro de um horrível aniquilamento" (NIETZSCHE, 1983, p.18). De um lado, é necessário dissimular a exploração que constitui as relações de trabalho através da crença sedutora na "felicidade terrestre para todos", da crença no advento de uma sociedade igualitária. De outro, não apenas os trabalhadores, mas também os comerciantes e banqueiros estão submetidos à "estupidez da mecânica" que caracteriza a sociedade moderna, na qual o rendimento e o consumo são referências supremas de valor. Nietzsche expressa com bastante clareza este pensamento em um aforismo de Humano Demasiado Humano:

A infelicidade dos homens ativos é que sua atividade é quase sempre um pouco irracional. Não se pode perguntar ao banqueiro acumulador de dinheiro, por exemplo, pelo objetivo de sua atividade incessante; ela é irracional. Os homens ativos rolam como pedra, conforme a estupidez da mecânica. - Todos os homens se dividem, em todos os tempos e hoje também, em escravos e livres; pois aquele que não tem dois terços do dia para si é escravo, não importa o que seja: estadista, comerciante funcionário ou erudito. (NIETZSCHE, 2000b, aforismo 283, p.191)

O termo "escravo" nada tem a ver, na interpretação de Nietzsche, com formas de estratificação econômica e social, mas com uma determinada forma de exercício do poder, na qual se desenvolve, em todos os níveis, um processo de nivelação do indivíduo. A estupidez da mecânica que rege a "incessante atividade" dos homens modernos, sejam eles operários, funcionários ou banqueiros, é contraposta a um tipo de atividade superior, aquela que caracteriza os "seres individuais e únicos". Na época moderna não são os indivíduos singulares, mas os "escravos" que determinam as representações comuns e para garantir sua existência designam "com nomes enganosos" suas relações com o mundo (NIETZSCHE, 1988a, p.765; p.41).

O discurso dos direitos fundamentais do homem, baseado em uma concepção do valor da humanidade como tal, independente do poder de criação e auto-superação de si próprio, é, para Nietzsche, um sintoma do processo de nivelação do homem moderno. As ideologias modernas do progresso, a crença de que a tecnologia levará à supressão da desigualdade e à instalação de uma sociedade solidária, são expressões de um processo global de adaptação e nivelamento. Nietzsche caracteriza o contexto de desenvolvimento do Estado moderno como um contexto de enfraquecimento da esfera política, de graves conseqüências para a arte e para a sociedade (NIETZSCHE, 1988a, p.772; p.49). Em contraposição ao Estado grego, onde predomina o "instinto político" e uma relação orgânica com a sociedade, na época moderna ocorre um processo de instrumentalização do Estado, de sua subordinação aos interesses de uma aristocracia financeira. Para alcançar seus objetivos, esses grupos devem desvincular o Estado de sua política de guerra e organizá-lo de modo a garantir a segurança e estabilidade ne- 
cessárias para administração e expansão dos interesses econômicos. A estratégia política é difundir "a concepção liberal e otimista de mundo, que tem como base o esclarecimento e a Revolução Francesa"(NIETZSCHE, 1988a, p.773; p.50-1), com o fim de se apropriar do egoísmo das massas e de seus representantes, de seu desejo de paz e estabilidade social.

Esse processo revela, para Nietzsche, a estreita articulação, dissimulada no discurso moderno, entre igualdade e utilitarismo. Em um sistema onde o direito de igualdade para todos se coloca em primeiro lugar, torna-se necessário a criação de processos de nivelamento através de mecanismos econômicos e sociais. As diferenças entre os homens são interpretadas como diferenças de papéis sociais, os quais são sempre substituíveis, assim como os ideais e toda esfera do que é qualitativamente diferente são reduzidos ao domínio de interesses calculáveis (VAN TONGEREN, p.5). No cálculo dos interesses predominarão os mais fortes, os que são comum ao grande número e que correspondem aos interesses de auto-conservação, ao ideal do trabalho aliado ao anseio de tranqüilidade e conforto. O interesse de determinados grupos econômicos, a esfera do cálculo dos interesses, é capaz de absolver o interesse geral, produzindo e generalizando a máxima "da maior felicidade para o maior número". Nietzsche procura elucidar o processo crescente de mediocrização implicada no moderno mecanismo de poder, pelo qual é produzido o animal de rebanho útil e trabalhador. A divisão do trabalho é descrita como um princípio de barbárie, um processo de dissociação das partes, a qual supõe a "dominação do mecanismo" . 5 O indivíduo se enfraquece através do processo de atomização do trabalho, o qual não apenas produz efeitos na personalidade do trabalhador, como o transforma em uma peça de um mecanismo desconhecido: "A fábrica reina. O homem torna-se um parafuso" (NIETZSCHE, 1988b, 9(64), p.298). Nietzsche chama atenção para o utilitarismo oculto no discurso igualitário, pelo qual o aumento da produção e dos ganhos significa uma perda, a saber, a diminuição do valor do tipo homem.

Nietzsche desenvolve uma interessante reflexão sobre os princípios da educação moderna e sobre as reivindicações de igualdade do movimento feminista de sua época, mostrando como neles se manifesta este processo de nivelamento e redução das diferenças. Vimos como a disputa era um elemento central da formação da juventude grega, através dela os jovens desenvolviam sua personalidade procurando chegar a melhor expressão de si próprio, ao mesmo que tempo que sua vitória não possuía um fim em si, mas estava associada à glória e ao benefício de sua cidade natal. O egoísmo e

5 NIETZSCHE, 1988b, fragmento póstumo 3(44), p.73. Nas próximas citações indicarei o número do fragmento póstumo e da página. Ver, também, o artigo de MÜLLER-LAUTER, 1999, p.127-8. 
ambição encorajados através da disputa encontravam, dessa forma, seus limites e integravam-se nas atividades coletivas da cidade. Os educadores modernos, por sua vez, procuram afastar o princípio do egoísmo das práticas educativas. Esta é, segundo Nietzsche, uma característica fundamental da modernidade: a aversão não apenas ao que é distante e singular, mas ao antagonismo e à disputa. Esta aversão se expressa na tendência moderna de dissolução das antigas relações de autoridade e hierarquia, pela qual se suprimem as diferenças entre jovens e velhos, entre homens e mulheres, ou em outras palavras, se perpetua e expande o processo de tornar a todos iguais.

Nesse contexto, Nietzsche coloca em questão o ponto de vista moderno, segundo o qual a condição das mulheres gregas era "indigna" ou "contrária à natureza" (NIETZSCHE, 1988b, 7(31), p.145). Esse argumento é expressão de uma sociedade que tem como princípio a "formação cultivada" da mulher moderna, assim como a aspiração à independência econômica e à participação nas atividades antes reservadas aos homens (NIETZSCHE, 1988b, 7(122), p.170-6). A fim de refutar este ponto de vista, Nietzsche descreve, de diferentes perspectivas, a dignidade da mulher grega, cuja esfera de atividades estava em grande parte restrita à família, e compara seu papel na sociedade nada menos que ao papel do Estado. Diferentemente do homem, a mulher possui uma afinidade mais profunda com a natureza, permanece no essencial sempre igual a si própria, representando as forças curativas e criadoras da natureza. Nietzsche observa que a mulher representa para o Estado, o que o sono representa para o homem. Embora o sono aparentemente nada realize, permaneça igual, nele reside "a força que cura (heilende Kraft) e que repara o que está esgotado", "a calma na qual toda desmedida se limita, o eternamente idêntico no qual se estabiliza o que ultrapassa e excede" (NIETZSCHE, 1988b, 7(122), p.171). A mulher está ligada, em grande parte, à esfera da família, é ela que engendra os "grandes filhos", assim como representa o suporte fundamental das gerações futuras. Aqui a natureza, como manifestação da conservação da espécie, "fala particularmente nas mulheres". Em situações de desordem ou de declíneo do poder instituído, a mulher é chamada a substituir, de certa forma, o Estado arruinado, atuando como força de coesão e proteção da estrutura familiar. Como suporte das novas gerações, a mulher possui "força premonitória", assim como a sabedoria e o dom divinatório das profetizas, cuja maior expressão é a Pítia. Também aqui se manifesta, segundo Nietzsche, seu papel de orientação como um papel complementar ao do Estado. Enfim, como expressão da natureza, a mulher traz em si não apenas as forças de cura e criação, mas também de destruição, sendo associada a elementos obscuros e desconhecidos, à "fonte do mal", como foi o caso da guerra de Tróia (NIETZSCHE, 1988b, 7(39), p.148). 
Muitos anos depois, em Para além de bem e mal, Nietzsche retoma o tema da especificidade do feminino, desenvolvendo argumentos bastante semelhantes aos elaborados em sua juventude. No aforismo 239, ele observa: "Uma mulher que perde a intuição do terreno onde vencerá mais certamente, que desdenha exercitar a arte de suas armas próprias; (...), o que isto tudo significa senão a ruína de todos os instintos femininos, não renuncia ela a ser mulher? (...) O que na mulher inspira respeito e, com bastante freqüência, temor, é sua natureza, mais 'natural' que aquela do homem" (NIETZSCHE, 1988c, p.176-8). O interessante na argumentação de Nietzsche é procurar o valor da mulher em seu terreno específico, naquilo que se constitui como o espaço próprio ao feminino, procurando restituir a diferença que se perde no processo moderno de produção de identidades. ${ }^{6}$ Seu objetivo é mostrar que a reivindicação de direitos iguais aos do homem não significa a emancipação da mulher, mas um gradual enfraquecimento das forças e da natureza propriamente femininas, representando um sintoma do processo geral de nivelação.

O mecanismo de nivelação desse sistema, se desenvolve, segundo Nietzsche, através da exclusão da luta e das relações antagônicas, ele não admite o conflito capaz de engendrar novos projetos e interpretações. $\mathrm{O}$ movimento esclarecido se interpreta como sentido e fim de toda história, como se o curso e evolução históricos se justificassem precisamente do ponto de vista do homem moderno. Não são apenas herdeiros, mas "cumes e alvos do processo universal" (NIETZSCHE, 1980, p.182). Nietzsche identifica nos diversos projetos de emancipação, que possuem em comum a firme crença na supressão da desigualdade entre os homens, uma continuidade, sob forma secularizada, do cristianismo. Enquanto este constrói uma interpretação absoluta da existência, a partir da qual a multiplicidade de tipos de homem é reduzida a um único ideal, o europeu moderno sacraliza os valores que constituem sua forma cultural específica, colocando-se como sentido e fim da própria história. Se antes o fim era Deus, agora é o próprio homem, e precisamente o homem nesta interpretação unívoca. Através da produção de valores universais, segundo os quais a igualdade e dignidade são atribuídas ao homem em si, o esclarecimento dissimula sua própria particularidade histórica, assim como exclui e afasta o desenvolvimento de novas possibilidades.

Por trás da constituição de valores universais encontra-se, segundo Nietzsche, uma determinada relação com a natureza. O que se faz passar por valores absolutos não é senão um meio de sobrevivência, uma forma de

6 Sobre a contribuição da reflexão nietzscheana para o movimento feminista contemporâneo ver ANSELL-PEARSON, 1997, p.194-211. 
conservar o respeito a si em uma situação de secreto desprezo pela existência. A sociedade moderna não quer admitir a ausência de dignidade, que ela mantém como um álibi, cuja função é reproduzir os mecanismos de exploração e dissolução da diferença. Nietzsche quer chamar atenção para a profunda correlação entre o processo de afirmação dos valores de dignidade e a produção simultânea dos meios de sua destruição, pela qual se torna visível a ambivalência do movimento esclarecido. A constituição de leis universais, que determina o princípio da igualdade para todos, corresponde a um processo de dissolução de toda diferença e antagonismo entre as forças, no qual "toda diferença de força se neutraliza na medida comum da impotência" (GIACOIA JÚNIOR, 1997, p.27). Esta redução da força à "medida comum" significa, no plano da cultura, a disseminação do gosto contra as naturezas criativas e em favor dos medíocres. Esta redução da força ao mínimo de sua vitalidade caracteriza fundamentalmente a relação ente cultura e natureza na modernidade. Os valores modernos, resultantes de um movimento de negação da força, expressam um declínio de vitalidade cujo poder se concentra na conservação da existência. A modernidade caracteriza-se por uma forma destrutiva de exercício de poder, na qual a dignidade do trabalho se dissolve nos mecanismos de exploração, a liberdade se converte em uniformidade através do processo de tornar igual.

A partir da análise de cultura grega, Nietzsche mostra como a escravidão era considerada um ultraje e, ao mesmo tempo, uma necessidade, a partir da qual uma classe era liberada da luta pela existência, a fim de satisfazer o surgimento de um mundo novo de necessidades. Essas necessidades são descritas como formas de transcendência, seja através da experiência artística de criação, seja através do princípio de superação de si, na qual a disputa colocava os cidadãos em uma situação de permanente rivalidade e luta, através da qual afirmavam seu talento e singularidade. Enquanto no mundo grego as lutas de domínio e desigualdades sociais eram explicitadas, assim como as relações de diferença e antagonismo eram incentivadas e integradas às manifestações de arte e cultura, na sociedade moderna igualitária e democrática, a crueldade e a violência se manifestam de forma mais profunda. Na modernidade, caracterizada pelos valores de igualdade, a sociedade torna-se instrumento de um processo ilimitado de exploração, que se desenvolve em escala planetária, e cujo crescimento supõe um aprofundamento dos mecanismos de controle e dissolução da singularidade.

O que interessa a Nietzsche é desenvolver uma discussão sobre a moderna sociedade do trabalho a partir de uma genealogia dos valores, em cujo centro encontra-se a pergunta pelo valor da existência. A análise da sociedade grega tem um objetivo bastante preciso, o de mostrar como os gregos desenvolveram, a partir da experiência dos aspectos terríveis da existência, uma concepção pessimista que, no entanto, não se dirigia con- 
tra a vida. Em O Nascimento da Tragédia a arte trágica é apresentada como uma forma singular de arte, pois transforma a realidade das forças dionisíacas em representações que tornam a vida possível. Aqui repousa o significado decisivo da união entre Apolo e Dioniso: a contradição que não pode ser suprimida, os dois polos extremos de nossa existência, formam um elo indissociável. A culpa, como observa Hufnagel (2000, p.50), torna-se uma culpa sem reparação possível, a qual transcende o sofrimento individual e constitui a tragicidade da existência humana. Justamente porque a existência não tem valor em si, não pode ser justificada senão como fenômeno estético, ela supõe uma experiência radical de afirmação, justamente a experiência que a arte trágica torna possível.

É neste contexto que se deve compreender a afirmação desenvolvida em "O Estado Grego": "A miséria dos homens que vivem penosamente ainda tem de ser aumentada para possibilitar, a um número limitado de homens olímpicos, a produção de um mundo artístico"(NIETZSCHE, 1988a, p.767; p.43). O objetivo de Nietzsche é tornar atual e significativa a pergunta pelo valor da existência, a qual implica em interrogar os fins pelos quais deve o tipo homem ser conservado. Esta pergunta, impossível em uma época encantada pelas promessas do progresso tecnológico e marcada por conflitos sociais que, eles também, estão ligados a projetos de libertação da exploração e desigualdade sociais, só pode ser formulada, se quer encontrar ouvidos, de modo explicitamente provocativo. A contraposição entre a cultura grega e moderna tem justamente o objetivo de fazer uma provocação que pode ser formulada nos seguintes termos: não são nas políticas de emancipação, na crença na possibilidade de exclusão das desigualdades e injustiças, que a existência humana encontra seu sentido e sua justificação, mas sim na criação da obra de arte genial, pela qual a contradição insolúvel, trágica, dessa existência, a qual está ligada à ambivalência da Humanização, pode tornar-se um elemento profundo de reflexão e de formação de uma cultura.

Nesse mesmo contexto, Nietzsche faz a seguinte afirmação: "A partir do que foi dito, temos de consentir em apresentar, como o eco de uma verdade cruel, o fato de que a escravidão pertence à essência de uma cultura: decerto, com esta verdade não resta mais nenhuma dúvida quanto ao valor absoluto da existência" (NIETZSCHE, 1988a, p.767; p.43). A expressão "verdade cruel" parece conter uma significativa alusão à República, particularmente ao mito da autarquia, criado por Platão para descrever as três principais classes da sociedade e suas diferenças de composição. Segundo este mito, que foi denominado também de "mentira nobre"7, as classes são cons-

7 Cf. PLATÃo, 414 d, 1996. Ver sobre esse tema a observação de ANSELL-PEARSON, 1997, p.72. 
tituídas de diferentes metais, a saber, o ouro, que forma a classe mais rara, dos reis-filósofos, a prata, correspondente à classe dos guardiães e o bronze, que forma a classe dos trabalhadores e agricultores. A expressão "verdade cruel" é utilizada justamente na passagem em que Nietzsche atribui a escravidão, enquanto expressão da hierarquia e relações de forças em uma sociedade, à "essência de uma cultura". Platão, ao contrário, inventa um mito, ou uma "nobre mentira", para explicar a gênese das diferenças e hierarquias de funções, da estruturação orgânica em escalões, que caracteriza a Cidade. ${ }^{8}$ Com isso, Platão dissimula as diferenças efetivas a partir das quais se formam os escalões, assim como sua estrutura hierárquica, as quais tem como base, em última instância, a exigência de ser o conhecimento da verdade a norma suprema que deve reger o Estado. Para reger o Estado perfeito é necessário possuir o conhecimento do Bem, princípio supremo de orientação de toda a vida da Cidade.

O otimismo platônico com o conhecimento, orientado pela crença na possibilidade de não apenas conhecer, mas "corrigir o ser" é expressão, segundo Nietzsche, de uma profunda negação da existência, de seu aspecto terrível e problemático. Platão inaugura a oposição entre sensível e suprasensível, a partir da qual se estabelece a desqualificação do mundo da aparência e do devir em proveito do mundo verdadeiro, das essências estáveis e eternas. A depreciação da existência contida nesse gesto é decisiva e constitutiva de toda história da metafísica ocidental. Nietzsche procura inverter o procedimento platônico nada menos que com a afirmação de "uma verdade cruel", segundo a qual a escravidão, as relações de domínio e expansão da força, constituem a essência de uma cultura. ${ }^{9}$ Esta verdade, pela qual é explicitada a relação indissociável entre cultura e natureza, assim como a violência das lutas de domínio e sua lógica destrutiva, foi dissimulada pela metafísica ocidental através da depreciação do mundo sensível e da instauração de uma instância inteligível, livre do aspecto transitório e finito desta existência, que regula a determinação dos códigos de valores.

A estratégia de Nietzsche é tornar pensável a verdade cruel, sem que este pensamento tenha um efeito destrutivo. E é justamente no interior dessa estratégia que se deve compreender o estatuto da Grécia antiga em sua reflexão. Não se trata de um retorno ou de um renascimento da arte e

8 No ensaio "Da utilidade e dos inconvenientes da história para a vida", elaborado alguns anos mais tarde, Nietzsche designa a mentira platônica "mentira necessária" (Notlüge) e contrapõe a essa mentira uma "verdade necessária". Cf. NIETZSCHE, 1980, p.199.

9 Em "O Estado Grego", Nietzsche caracteriza a escravidão como resultado de relações de força, das lutas de domínio que formam e mantêm o Estado. Não se trata, portanto, de essência no sentido de algo a-histórico, independente das relações transitórias e mutáveis de domínio. Cf. NIETZSCHE, 1988a, p.770; p.46. 
da cultura grega antiga na modernidade, como se esta cultura se tornasse um modelo a ser imitado. Trata-se, antes, de contrapor às crenças modernas uma estrutura de valores radicalmente diferente, caracterizada por uma visão de mundo onde a esfera das necessidades, o trabalho e a luta pela existência, não é valorizada, ao mesmo tempo que a arte alcança elevadas formas de manifestação. A partir do contraste entre duas diferentes estruturas de valores, Nietzsche procura provocar um impacto nas formas de pensamento cristalizadas na modernidade, a fim de restituir a historicidade das formações culturais modernas, apagada pela crença na universalidade dos valores. O contraponto provocativo entre escravidão e dignidade do trabalho, entre liberdade e supressão da diversidade tem como objetivo tornar possível um distanciamento das posições ideológicas predominantes na modernidade, de modo que o "óbvio" possa aparecer como problemático, assim como o "universal" seja confrontado com seu caráter histórico. O recurso à história permite a Nietzsche abrir espaço para formas de pensamento que rompem com os critérios habituais, particularmente os valores de igualdade e o ideal moderno de conservação de si, a partir das quais possam se formar novos valores. O ensaio "Estado Grego" pode ser entendido como um exercício de auto-reflexão, no qual a interpretação da Grécia fora da estrutura do modelo humanista, a afirmação de uma unidade indissociável entre natureza e cultura procura restituir a relação de experimento com o pensamento. Nietzsche não anuncia programas de mudanças sócio-políticas, assim como não oferece um diagnóstico concreto da modernidade política. Seu objetivo é, vale ressaltar, tornar pensável as relações de dominação, a lógica destrutiva que caracteriza o processo civilizatório. Esse poder pensar supõe um profundo confronto com o aspecto trágico da existência, confronto este que não pode ser separado de uma postura em relação ao presente que Nietzsche denominou de "intempestiva" e que dará título aos ensaios publicados no período imediatamente posterior à elaboração de "O Estado Grego":

Esta consideração é também intempestiva, porque considero como um mal, como uma deficiência, uma coisa da qual o tempo presente se orgulha, a sua cultura histórica; (...) Não vou negar que foi de mim principalmente, e dos outros só a título de comparação, que retirei as experiências que deram origem a este sentimento que me incomoda - mesmo que seja apenas na medida em que sou discípulo da antigüidade grega, que eu venha a experimentar sentimentos tão pouco atuais, apesar de me sentir filho do tempo presente. Mas é uma liberdade que me concedo a mim próprio, enquanto filólogo clássico, porque não vejo para que poderia servir a filologia clássica de nosso tempo, senão para lançar uma ação intempestiva contra esta época, sobre esta época e, assim o espero, em benefício do tempo que há de vir. (NIETZSCHE, 1980, p.102-3) 
É como discípulo da antigüidade grega, como um tipo de olhar fora de seu tempo - inatual - e portanto a partir de uma outra estrutura de valor, que Nietzsche desenvolve sua crítica à modernidade, crítica esta que tem o papel de lançar uma "ação intempestiva" contra sua época, ou seja, uma ação capaz de criar um distanciamento em relação aos valores em curso, de tornar a época reflexiva sobre si própria, liberta dos valores que constituem sua "aeterna veritas". Pode-se dizer que a reflexão de Nietzsche sobre o Estado grego é a primeira "ação intempestiva" sobre a época moderna, a partir da qual o contraste entre diferentes culturas, o jogo permanente entre possibilidades opostas de pensamento, tem como objetivo experimentar novas perspectivas de análise, amadurecendo as condições para a criação de novos valores.

CAVALCANTI, Anna Hartmann. Art of experiment: politics, culture and nature in early Nietzsche. Trans/Form/Ação, (São Paulo), v.30(2), 2007, p.115-133.

- ABSTRACT: This article intends to analyse the relationship between Nietzsche's political thought and his critique of culture, as elaborated in notes and essays during the first period of his work, particularly in Five Prefaces to five non-written Books. The goal is to show how the philosopher attempts, based on a singular analysis of the State and society in ancient Greece, to restore to the political experience a reflexive dimension in decline in the modernity.

- KEYWORDS: politics; culture; nature; Nietzsche.

\section{Referências bibliográficas}

ANSELL-PEARSON, K. Nietzsche como pensador político. Rio de Janeiro: Jorge Zahar, 1997.

GIACOIA JÚNIOR, O. "O Platão de Nietzsche. O Nietzsche de Platão". São Paulo, Cadernos Nietzsche. n. 3, 1997.

HAAR, M. Par-delà le Nihilisme. Paris: PUF, 1998.

HOBBES, T. Leviatã ou Matéria, Forma e Poder de um Estado Eclesiástico e Civil. 3.ed. São Paulo: Editora Abril Cultural, 1983.

HUFNAGEL, E. "Nietzsche als Provokation für die Bildungsphilosophie. Versuch den Griechischen Staat zu lesen". In: Nietzscheforschung. Jahrbuch der Nietzschegesellschaft. v.7, 2000.

JÄGER, W. Paidéia; A formação do homem grego. São Paulo: Martins Fontes/ Universidade de Brasília, 1986.

MÜLLER-LAUTER, W., "De L'Économie et de la Culture chez Nietzsche". In: LE RIDER, J. (org.) Nietzsche Moraliste. Révue Germanique Internationale. Paris, n.11, 1999. 
NIETZSCHE, F. "Da utilidade e dos inconvenientes da história para a vida". In: Considerações Extemporâneas. Lisboa: Editorial Presença / Martins Fontes, 1980. Obras Incompletas. 3.ed. Trad. Rubens Torres Filho. São Paulo: Editora Abril Cultural, 1983.

Sämtliche Werke Kritische Studienausgabe (KSA). hrg. v. G. Colli e M. Montinari. v.1. München: Walter de Gruyter, 1988a.

"Nachlaß 1869-1874" In: Sämtliche Werke Kritische Studienausgabe. (KSA) hrg. v. G. Colli e M. Montinari. v.7. München: Walter de Gruyter, 1988b. "Jenseits von Gut und Böse". In: Sämtliche Werke Kritische Studienausgabe. hrg. v. G. Colli e M. Montinari. v.5. München: Walter de Gruyter, 1988c. Kritische Gesamtausgabe Werke III, 5/1-2. hrg. v. Michael Kohlenbach e Marie-Luise Haase. Nachbericht zur dritten Abteilung. Berlin-New York: Walter de Gruyter, 1997.

Cinco prefácios para cinco livros não escritos. Trad. Pedro Süssekind. Rio de Janeiro: Sette Letras, 2000a.

Humano Demasiado Humano. Trad. Paulo César de Souza. São Paulo: Companhia das Letras, 2000b.

PLATÃO. A República. 8.ed. Lisboa: Fundação Calouste Gulbenkian, 1996.

ROUSSEAU, JJ. Discurso sobre a origem da Desigualdade entre os homens. Brasília: Universidade de Brasília, 1987.

VAN TONGEREN, P. "Der freie Geist und die Demokratie".

In: http: //www.hypernietzsche.org/pjmvantongeren-1. 